\title{
Carbon Footprint and Total Fuel Consumption Benefit Evaluation of a Proposed Decision Support System Algorithm for Istanbul Ataturk Airport Surface Movement Area
}

\author{
Orhan Ertugrul Guclu \\ TF-X Project, Turkish Aerospace, Ankara, Turkey \\ E-mail: orhanertugrulguclu@gmail.com
}

\begin{abstract}
The continuous growth in air traffic volume causes extra operational fuel consumption due to serious ground delays at major airports. Effective ground movement management of aircraft plays an essential role in reducing or even eliminating these ground holds and congestions. Ground movement of aircraft is conventionally done by ground controllers using conventional techniques, which rely on static and short-term (dynamic) planning. Such planning usually overlooks possible in-flight delays, which lead to gate assignment problems (GAP) at destination airports. Ground movement decision support system is proposed as an alternative method to mitigate these problems. This system allocates available taxi paths to arriving and departing aircraft. Such a dynamic planning provides more robust taxi path assignment and delay management at the airports movement area especially in the peak hours. This study analyzes time benefits and time cost effects of this system using SIMMOD, which is a fast time simulation tool. In order to demonstrate the fuel consumption benefits of tactical taxi path allocation, two scenarios (baseline and alternative), have been generated and tested for Istanbul Ataturk Airport.
\end{abstract}

Keywords: Airport Modeling, Carbon Footprint, Heuristic Algorithm, Airport Ground Delays, Air Traffic Management

DOI: $10.7176 / \mathrm{JSTR} / 6-04-06$

\section{Introduction}

The major problem of international airports is the lack of capacity to meet the growing traffic demands since most of them have no or limited facilities for physical development. Therefore, the only way to overcome this problem is to manage the airport's traffic efficiently. The efficient traffic management strongly depends on the performance of air traffic controllers, ground services and pilot reaction time. The decision support systems are not only to increase their performance but also reduce delays and fuel consumption at airports.

Ground delays at taxiway intersections are one of the major contributors of delays and congestions at airports. They usually occur because of inefficient taxi path assignment for arriving aircraft. Taxi path is the route of aircraft for arrival aircraft from runway end to the parking position, for departure aircraft from parking position to the runway entrance. The possible alternatives for taxi path depends on the predefined taxi routes which restricts the number of alternative taxi paths. However, to lessen the amount the predefined routes causes to increase the ground conflict possibility. This trade-off for taxi path allocation should be managed efficiently to reduce the ground delays at airports.

In 1990's, due to the huge increase in carbon emission and pollution in the airports, the air service providers decided to price the emissions of the aircraft by their aircraft type. One of the initial appliers of this pricing was Lyon-Satolas Airport (Perl et. al., 1997). Perl et al. examined the cost of the air pollution in Lyon to lessen the uncertainty of the pricing chart. They have divided the emission costs into four parts, which are road transport, waterway transport, urban transit and airport. In 1992 the air pollution percentage caused by airports was around 4.3, although their projection about 2015 was 6.9. Heland and Schafer studied on the Fourier Transform Infrared emission spectroscopy (Heland \& Schafer, 1998). According to their study, they had aimed to investigate the emissions in exhausts of several

44 | P a g e

www.iiste.org 
operating aircraft engines at ground-level FTIR emission spectroscopy as a remote sensing analysis method. As a result, they found the exhaust emission differences of the airport.

Petersen and Solberg compared the use of glulam beams at the new airport outside Oslo with an alternative solution in steel in order to make an inventory of greenhouse gas (GHG) emissions and energy use over the life cycle of glulam and of steel, calculate the avoided GHG emissions and the cost of the substitution, and analyze which factors have the strongest influence on the results (Petersen \& Solberg, 2002). Their results showed that the total energy consumption in manufacturing of steel beams is two to three times higher and the use of fossil fuel 6-12 times higher than in the manufacturing of glulam beams. Unal et. al. quantifed the impact of aircraft emissions on regional air quality, especially in regards to PM2.5 and ozone at Hartsfield-Jackson Atlanta International Airport (Unal, 2005). They estimated using a first-order approximation where aircraft PM2.5 emissions rate are a function of SN and fuel flow rate for different engine types in different modes of operation.

For the subset of hydrocarbons Herndon et. al. measured the idle emissions levels relative to normaldehyde agree well with those of previous studies (Herndon et. al., 2006). This study indicated that the effective hydrocarbon emission index for idling in-use aircraft may be greater than that tabulated for idle at $7 \%$ rated thrust in the ICAO databank by $40-90 \%$.

Kesgin dealed with estimating aircraft landing and take-off cycle emissions ( $\mathrm{HC}, \mathrm{CO}, \mathrm{NOx}, \mathrm{SO} 2)$ at 40 Turkish airports including the biggest airports, i.e. Istanbul Ataturk Airport, Antalya Airport and Ankara Esenboga Airport in 2001 (Kesgin, 2006). Their estimations showed that 2 min decrease in taxiing time resulted in a decrease of $6 \%$ in LTO emissions.

Schürmann et. al. studied on the impact of emissions at an airport on local air quality (Schürmann et. al., 2006). They made a research about the measurement campaign at the Zurich airport with the measurements of $\mathrm{NO}, \mathrm{NO} 2, \mathrm{CO}$ and $\mathrm{CO} 2$. Their results showed that in re-fuelling emissions, a ratio well below 1 was found, while for exhaust this ratio was usually about 1.7 .

Herndon et. al. also, speciated hydrocarbon emission indices measured from in use commercial, air freight, and general aviation aircraft at Oakland International Airport to help airports improve emission inventory data (Herndon et. al., 2008). Using estimates of operational fuel flow rates at idle, their analysis suggested that the current emission inventories at the temperatures encountered at Oakland International Airport underestimate hydrocarbon emissions from the idle phase of operation by $16-45 \%$.

Mazaheri et. al. addressed the published particle number emission factors for aircraft operations in knowledge by utilizing recent progress in the quantification of aircraft particle emissions (Mazaheri et. al., 2011). They showed that the contribution of the climbout mode was considerably higher than for other individual LTO operational modes by the analysis of the LTO cycle contribution to the daily emissions. According to their results emissions of departing aircraft were slightly higher than arriving operations, due to the higher aircraft engine emission rates during takeoff and climbout.

Nikoleris et. al. presented a detailed estimation of fuel consumption and emissions during ground movements using aircraft position data from actual operations at Dallas/Fort Worth International Airport by making assumptions of the thrust level during each state, fuel flow and emission index values from International Civil Aviation Organization's databank (Nikoleris et. al., 2011). They found that the states of idling and taxiing at constant speed or braking were the two largest sources of fuel burn and emissions, and the model estimates were sensitive to the thrust level assumptions for these states. So, to minimize the fuel burn and emissions at ground movement stage of aircraft, an efficient ground management system should be applied to the airports.

These studies show the carbon emission at the airports should be at essential point, since the air traffic volume is increasing. The air traffic volume rise causes extra operational delays at the airports which increases the engine idle time. Therefore, exhaust emission at the airports also growths with the rate of air traffic volume rise.

Nikoleris et al. showed the taxiing at the constant speed, idling and breaking is the second largest fuel burn stage comes after take-off stage. So, the highest percent of the exhaust emission of an aircraft occurs around the airport.

In this study, the alternative taxi paths, which are created from predefined taxi routes, are examined through SIMMOD to minimize the ground holds. Alternative and baseline scenarios are created to be analyzed.

\section{Airport Layout And Parking Positions}

Istanbul Ataturk Airport is located $24 \mathrm{~km}$ west of the city at an elevation of $37 \mathrm{~m}$ above mean sea level shown in Figure 1. 


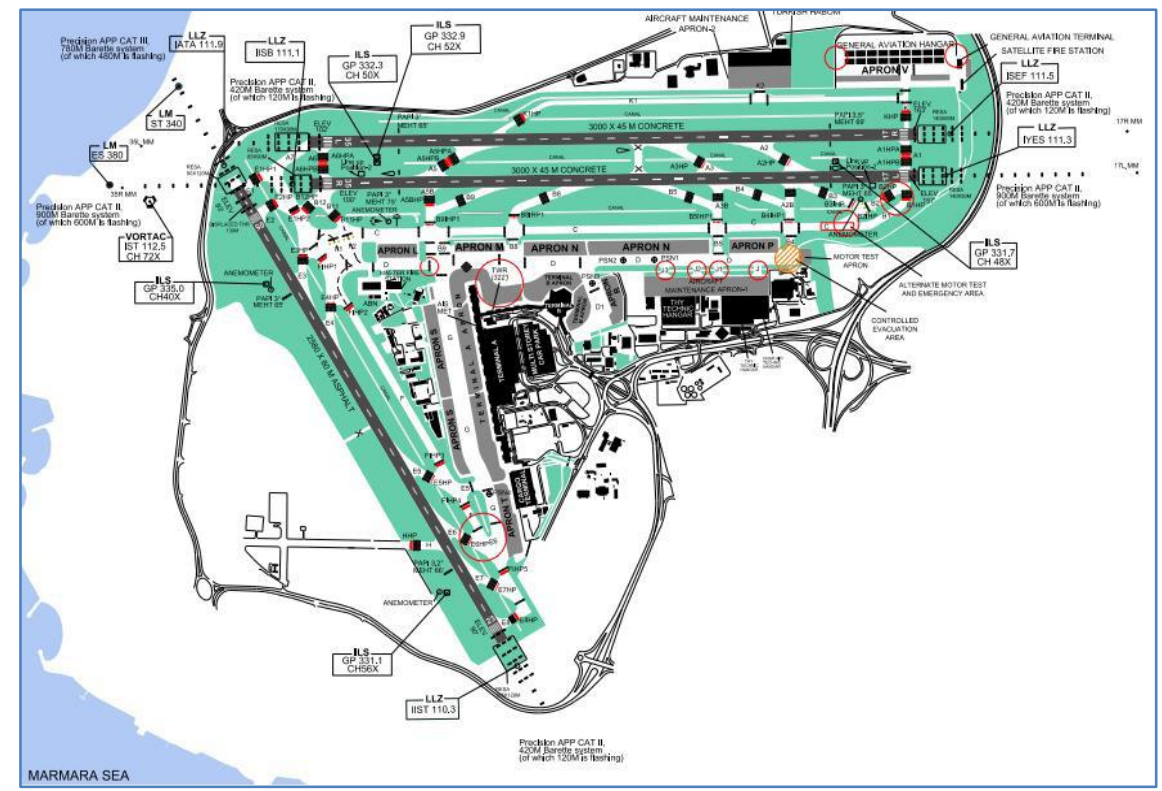

Figure 1. The layout of Istanbul Ataturk Airport (LTBA) (DHMİ, 2014)

The airport has three runways $(35 \mathrm{R} / 17 \mathrm{~L}, 35 \mathrm{~L} / 17 \mathrm{R}$ and $05 / 23)$, thirty-seven taxiways designated under eight groups (i.e. from $\mathrm{A}$ to $\mathrm{G}$, and $\mathrm{K}$ ), twelve terminal apron areas (i.e. terminal $\mathrm{A}$ and $\mathrm{B}$, remote aprons from $\mathrm{L}$ to $\mathrm{N}$ and $\mathrm{P}$ to $\mathrm{V}$, and maintenance aprons 1 and 2) as shown in Figure 1. The parallel runways $35 \mathrm{R} / 17 \mathrm{~L}$ and $35 \mathrm{~L} / 17 \mathrm{R}$ are $3000 \mathrm{~m}$ long and $45 \mathrm{~m}$ wide, whereas, runway $05 / 23$ is $2580 \mathrm{~m}$ long and 60 $\mathrm{m}$ wide. The highest throughput can be achieved using open $\mathrm{V}$ runway configuration with $35 \mathrm{R}$ for departures and 05 for arrivals (DHMI, 2014). 35L is usually used as a back-up for 35R when it is required.

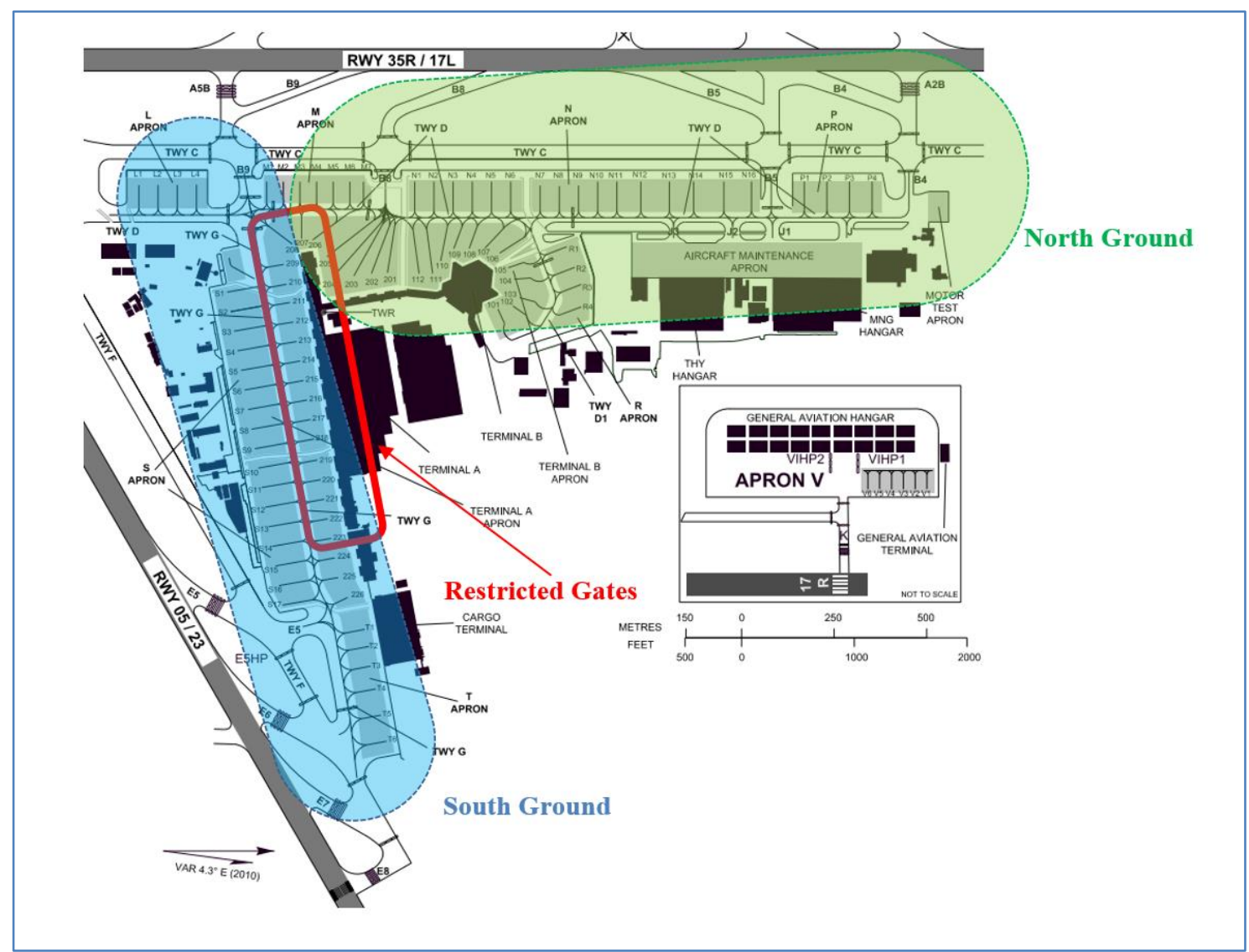

Figure 2. The layout of Istanbul Ataturk Airport (LTBA) (DHMI, 2014) 


\section{Traffic Analysis}

Istanbul Ataturk Airport is the Turkey's most crowded and the Europe's second crowded airport. Traffic operation amount in a day is around 1500 in 2016. To analyze the traffic detail of the airport, June 26th 2012 traffic data is used. The traffic summary of the peak period in June 26th 2012 is presented in Figure 3. During this four-hour period, 108 arrivals and 94 departures, totaling 202 operations, took place. The highest throughput was achieved between 18:00-19:00 with 58 operations of which 32 were arrivals and 26 were departures. According to the traffic data, all departures took-off either from $35 \mathrm{R}$ or $35 \mathrm{~L}$ except 5 of them from 05 , whereas all arrivals landed on 05 except one on 35R during the specified period. Of the traffic during this period, $89 \%$ were medium category aircraft and $11 \%$ were heavy category aircraft. The majority of the medium category aircraft belong to the Airbus A320 and Boeing B737 families, whereas the A330 family had the largest share among the heavy category aircraft. International and domestic flights had $62 \%$ and $38 \%$ shares of the total traffic, respectively.

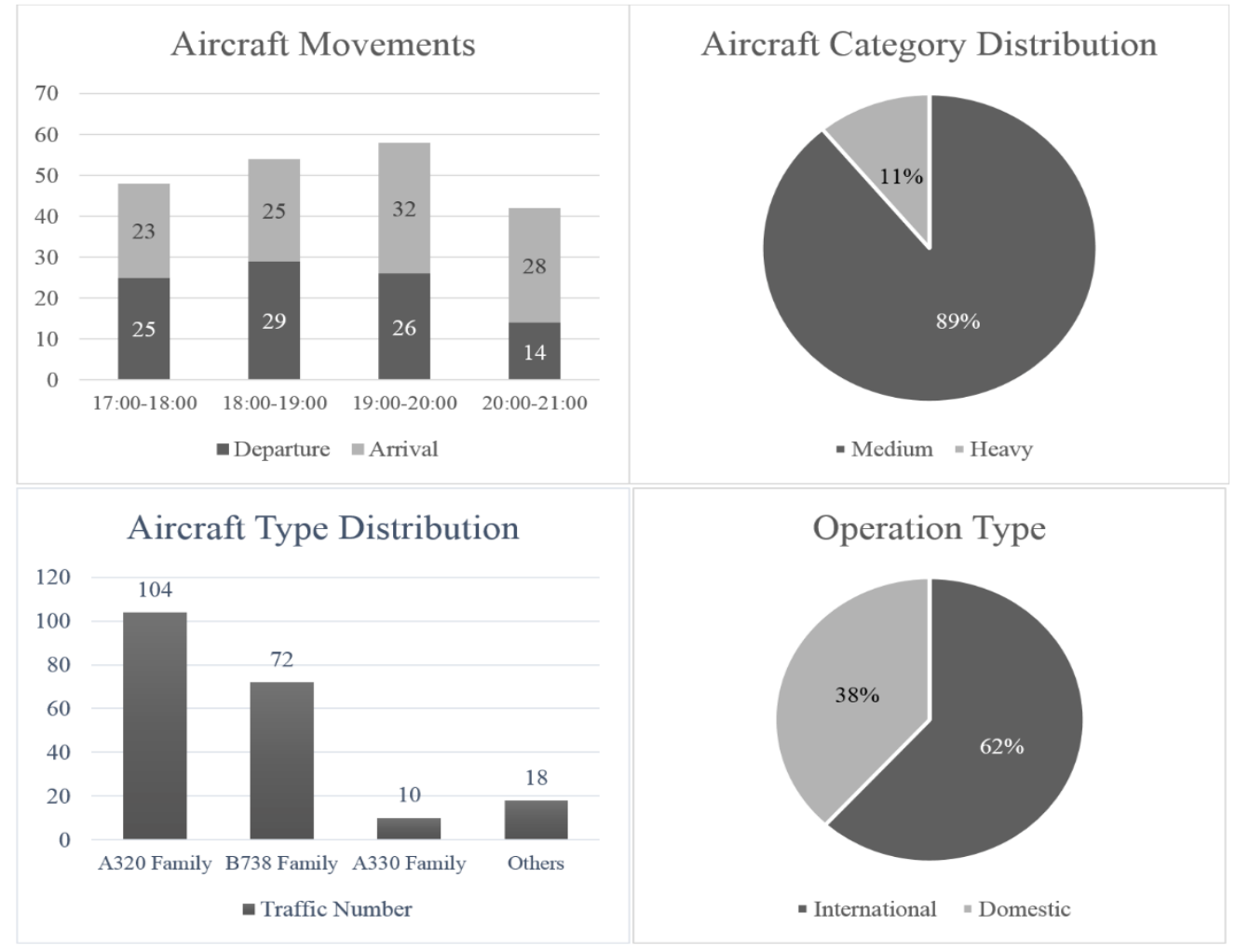

Figure 3. Traffic Analysis of 26th of June 2012 in terms of aircraft movements, categories, type and operation distribution between 17:00-21:00.

According to this analysis, at the peak hour 58 aircraft is operating while the extreme hour operation amount is around 72. In 2016, the peak hour and extreme hour operation amount reaches to 69 and 81 respectively. This increment shows that the in the peak hour the operation amount is increased approximately $\% 16$.

\section{Methodology}

First, Istanbul Ataturk Airport is modeled in SIMMOD based on the most recent Aeronautical Information Publication (AIP) data. Later, runway features, gate features, the directions of the taxiways and the holding points have been set. In the analysis, aircraft performance differences are ignored and a single aircraft and the most common type (B737-300) at Istanbul Ataturk Airport are chosen in order to generate the best case. Final approach separations of this type of aircraft have been decided as 5 miles. Landing and rolling probabilities on runway has been based on real values. Speeds and separations of aircraft on taxiways have been set from the real values of BADA. After completion of this design, we have started to the preparation of the scenario. In the results, we have calculated the typical idle fuel consumptions of the aircraft. The reason of choosing idle fuel consumption is while aircraft is taxing and waiting it consumes the fuel at the idle level. We have preferred B737 type of aircraft using CFM56-5B engine. Because flight operations in Istanbul Ataturk Airport mostly done with this type of aircraft using this engine. 


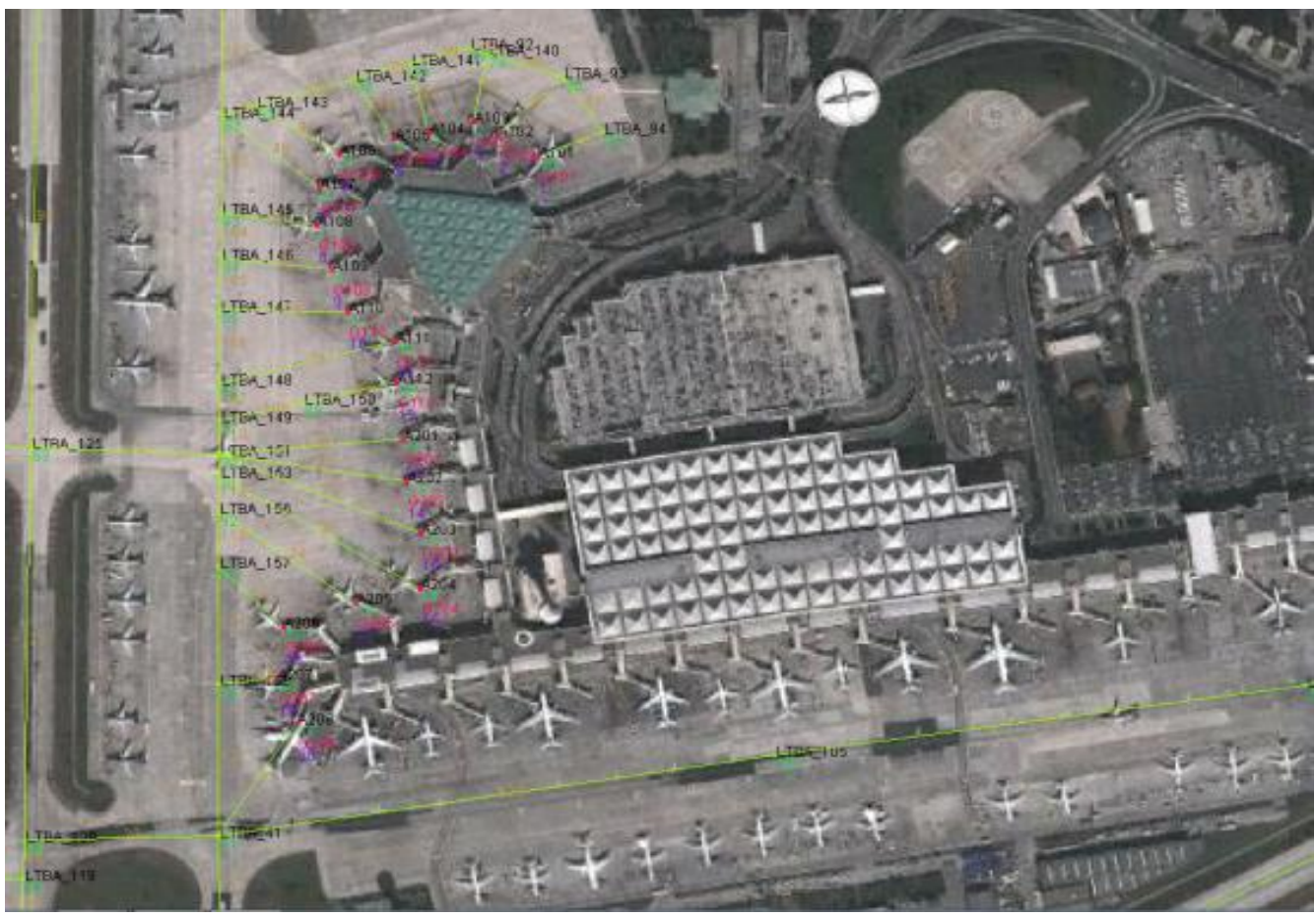

Figure 3. Istanbul Ataturk Airport taxiways model from SIMMOD

\section{Results}

The comparison of two scenarios, baseline and alternative is represented in Table 1. According to the Table 1 the total travel times of arriving aircraft for baseline and alternative scenario are $996.4 \mathrm{~min}$. and $896.9 \mathrm{~min}$. respectively. This shows that approximately 10 percent reduce was reached with a wellplanned ground movements of aircraft. While the arriving aircraft total travel time was reduced, the departing aircraft total travel time was increased $16.5 \mathrm{~min}$. which shows that the arriving aircraft has priority on taxi path planning. But when we compare the total travel times of departing and arriving aircraft, we see that 7.4 percent reduce was accomplished.

Table 1. Total results of Baseline and Alternative Scenario

\begin{tabular}{|c|c|c|c|c|c|c|c|c|c|}
\hline & \multirow{2}{*}{$\begin{array}{l}\text { LTBA- } \\
\text { All } \\
\text { Arrival } \\
\text { Flow }\end{array}$} & \multicolumn{3}{|c|}{$\begin{array}{l}\begin{array}{l}\text { Overall Arrival Times } \\
\text { (min.) }\end{array} \\
\end{array}$} & \multirow{2}{*}{$\begin{array}{l}\text { LTBA } \\
\text {-All } \\
\text { Dep. } \\
\text { Flow }\end{array}$} & \multicolumn{3}{|c|}{$\begin{array}{l}\text { Overall Departure Times } \\
\text { (min.) }\end{array}$} & \multirow{2}{*}{$\begin{array}{l}\text { Total } \\
\text { Travel } \\
\text { Times }\end{array}$} \\
\hline & & $\mathrm{Ta}$ & y & 1 & & $\mathrm{~T}$ & $y$ & Travel & \\
\hline & 39 & T & 589.2 & 0964 & 19 & 108.4 & 183 & 126 & 123.1 \\
\hline Altern & 9 & 404.5 & 492.4 & 896.9 & 19 & 114.6 & 28.6 & 143.2 & 1040.1 \\
\hline
\end{tabular}

Current ICAO Standards for emissions certification of aircraft engines are contained in Annex 16, Volume II (ICAO, 2008):

- The Engine Emissions Standards cover HC, CO, NOx and Smoke.

Table 2. Engine emissions standards cover

\begin{tabular}{|c|c|}
\hline Emissions & From 1 kg. Fuel \\
\hline $\mathrm{CO}_{2}$ & $3160 \mathrm{~g}$. \\
\hline $\mathrm{H}_{2} 0$ & $1290 \mathrm{~g}$. \\
\hline $\mathrm{NO}_{\mathrm{X}}$ & $15 \mathrm{~g}$. \\
\hline $\mathrm{SO}_{\mathrm{X}}$ & $1.2 \mathrm{~g}$. \\
\hline $\mathrm{CO}$ & $<0.6 \mathrm{~g}$. \\
\hline Hydrocarbons & $<0.01 \mathrm{~g}$. \\
\hline Particulates & $<0.05 \mathrm{~g}$. \\
\hline
\end{tabular}


According to these emission standards, an aircraft's exhaust emission can be calculated, if its fuel burn would be calculated. As we mentioned before, the aircraft is medium category and their engines are accepted as CFM56-5B. According to this engine's fuel consumption data at taxi and idle stage obtained from ICAO, the aircraft fuel burn is $0.202 \mathrm{~kg} / \mathrm{s}$. When we look at the Table 3, we see that $1006 \mathrm{~kg}$. of fuel burn difference is obtained with an efficient taxi path planning.

Table 3. Total Fuel consumption during two hours of simulation

\begin{tabular}{|l|c|c|c|c|}
\hline & $\begin{array}{c}\text { Overall Arrival } \\
\text { Times (min.) }\end{array}$ & $\begin{array}{c}\text { Overall Departure } \\
\text { Times (min.) }\end{array}$ & $\begin{array}{c}\text { Total Travel } \\
\text { Times (min.) }\end{array}$ & $\begin{array}{c}\text { Total Fuel } \\
\text { Consumption (kg.) }\end{array}$ \\
\hline Baseline & 996.4 & 126.7 & 1123.1 & 13611.972 \\
\hline Alternative & 896.9 & 143.2 & 1040.1 & 12606.012 \\
\hline
\end{tabular}

According to this fuel burn difference, the total emissions distribution depending on the engine emission standards are shown in Table 4. This table shows that a well-planned taxi path allocation reduces $\mathrm{CO} 2$, NOX and SOX, 3 tons, $15 \mathrm{~kg}$. and $1.2 \mathrm{~kg}$. respectively.

Table 4. Total exhaust emissions of 2 hours of simulation

\begin{tabular}{|c|c|}
\hline Emissions & From 1006 kg. Fuel \\
\hline $\mathrm{CO}_{2}$ & $3178.96 \mathrm{~kg}$. \\
\hline $\mathrm{H}_{2} 0$ & $1297.74 \mathrm{~kg}$. \\
\hline $\mathrm{NO}_{\mathrm{X}}$ & $15.09 \mathrm{~kg}$. \\
\hline $\mathrm{SO}$ & $1.2072 \mathrm{~kg}$. \\
\hline $\mathrm{CO}$ & $<0.6036 \mathrm{~kg}$. \\
\hline Hydrocarbons & $<0.01006 \mathrm{~kg}$ \\
\hline Particulates & $<0.0503 \mathrm{~kg}$. \\
\hline
\end{tabular}

\section{Conclusion}

The rapid increase in air traffic volume will cause essential health problems in a few years. To lessen the amount of carbon emission, green airports, which has the aircraft auto taxiing vehicles, should be the essential aim. If another ground vehicle does the movements of the aircraft at the airport, the aircraft's engine will not start until the take-off stage. This will reduce major part of the exhaust emission of aircraft. Beside this, airport collaborative decision tools should be used to minimize the ground delays and taxi times. As a future work of this paper, the carbon emission and its effects on the Istanbul New (Third) Airport will be analyzed to reduce its consequences.

An efficient taxi path allocation system is more suitable than the other methods because it can minimize the effects of delays considerably even in the best traffic cases. It provides less fuel consumption during air traffic control operations. From the fuel consumption results, we can see that it provides less exhaust emissions although in a small traffic operation simulation. Decision support tools using this kind of algorithm can be developed and installed to airport tower control units with much smaller costs. The rapid increase in air traffic volume will cause essential health problems in a few years. So that a well-planned airport management should be further aims of airport service providers.

\section{References}

DHMI, Statistics, http://www.dhmi.gov.tr/istatistik.aspx [cited 25 Dec 2014].

DHMI, AIP Turkey Aerodromes, General Directorate of State Airports Authority, Ankara, 2014.

EUROCONTROL, Market Segments in European Air Traffic, STATFOR Doc 534 v1, 2014

HELAND, J. SCHÄFER, K., (1998), Determination of major combustion products in aircraft exhausts by FTIR emission spectroscopy. Atmospheric environment, 32.18: 3067-3072.

HERNDON, Scott C., et al., (2006), Hydrocarbon emissions from in-use commercial aircraft during airport operations. Environmental science \& technology, 40.14: 4406-4413.

ICAO, (2008), Annex 16: Environmental Protection, Volume 2: Aircraft Engine Emissions. 
KESGIN, Ugur, (2006), Aircraft emissions at Turkish airports. Energy, 31.2: 372-384.

Mazaheri, Mandana; Johnson, G. R.; Morawska, Lidia, (2011), An inventory of particle and gaseous emissions from large aircraft thrust engine operations at an airport. Atmospheric Environment, 45.20: 3500-3507.

Nikoleris, Tasos; Gupta, Gautam; Kistler, Matthew, (2011), Detailed estimation of fuel consumption and emissions during aircraft taxi operations at Dallas/Fort Worth International Airport. Transportation Research Part D: Transport and Environment, 16.4: 302-308.

Perl, Anthony; Patterson, Judith; Perez, Marc, (1997), Pricing aircraft emissions at Lyon-Satolas airport. Transportation Research Part D: Transport and Environment, 2.2: 89-105.

Petersen, Ann Kristin; Solberg, Birger, (2002), Greenhouse gas emissions, life-cycle inventory and cost-efficiency of using laminated wood instead of steel construction.: Case: beams at Gardermoen Airport. Environmental Science \& Policy, 5.2: 169-182.

Schürmann, Gregor, et al., (2007), The impact of NOx, CO and VOC emissions on the air quality of Zurich airport. Atmospheric Environment, 41.1: 103-118.

Unal, Alper, et al., (2005), Airport related emissions and impacts on air quality: Application to the Atlanta International Airport. Atmospheric Environment, 39.32: 5787-5798. 